\title{
GROSS MORPHOMETRICAL CHANGES IN LEG BONES OF POST-HATCH MALE BROILER CHICKENS WITH SPECIAL REFERENCE TO GROWTH PLATE CARTILAGE
}

\author{
Minati Behera ${ }^{1}$, Srinivas Sathapathy ${ }^{1}$, Arun Kumar Mandal ${ }^{2 *}$ \\ Received 11 November 2021, revised 05 December 2021
}

\begin{abstract}
Forty-five (45) 'Vencob' day old male broiler chicks were reared up to day 42 (market age) to carry out gross morphometrical studies on the long leg bones (femur, tibiotarsus and tarsometatarsus) and associated growth plate cartilages at different ages (on days 1,7,14,21, 28, 35 and 42). It was found that the average weight of the bones in day old chicks gradually increased up to day 7 , followed by a marked increase from day 14 up to day 42 . There was simultaneous increase in length of the bones throughout the experimental period. The thickness of marrow cavity and cortical bone gradually increased with age of the broiler birds. The diameter (width) of all the bones in broiler birds showed a steep increase from day 7 up to day 21 and a steady increase thereafter till day 42 . The proximal and distal end widened more than the mid shaft and the distal end was the widest. The growth of the gross dimensions of the bones slowed down a bit towards the end of the experiment (days 35 and 42). Though initially mid shaft cortical bone was thinner than epiphyseal ends, it gradually became thicker from day 21 (in femur and tarsometatarsus) or from day 28 (in tibiotarsus) till day 42. The gross anatomical observation did not reveal the presence of growth plate cartilages in all day- old chicks. In femur, presence of growth plate cartilages was reported for the first time. These gross morphometrical parameters (data) could be well correlated with the musculoskeletal growth of the birds as well as with the common deformities of the long leg bones.
\end{abstract}

Key words: Gross morphometry, Leg bones, Growth plate cartilage, Broiler chicken.

\section{INTRODUCTION}

In recent years, there has been much genetic selection for faster growth and tender meat production in broilers (Kirkwood et al. 1989, Williams et al. 2000, Manohar et al. 2015). The desired genetic manipulation produces early muscle growth without a simultaneous increase in the skeletal development, thus resulting in leg weakness and disorders (Manohar et al. 2015). Moreover, there has been frequent incidence of skeletal problems in general and leg problems in particular (Williams et al. 2000, Applegate and Lilburn 2002). It is well recognized that the long leg bones (femur, tibiotarsus and tarsometatarsus) are principal weight bearing bones in poultry birds. Upper leg bones (femur and tibiotarsus) are heavily muscled and play very important role in locomotion and support. Legs play an important role in determining the degree of mobility of the limbs in birds (Sreeranjini et al. 2013). Biometrical parameters of these bones like length, width or diameter etc. are considered as good indicators of musculoskeletal growth in broiler chicken (Applegate and Lilburn 2002). In adult poultry, the length of the tarsometatarsal bone was correlated to the body weight (Naldo et al. 2000, Williams et al. 2000). The length and diameter of the leg bones were reported to be larger in fast growing broilers than in layer chickens (Breugelmans et al. 2007).

Any sort of disruption in normal development and growth of the epiphyseal growth plate cartilage is sure to

\footnotetext{
${ }^{1}$ Department of Anatomy and Histology, College of Veterinary Science and A.H., Odisha University of Agriculture and Technology, Bhubaneswar, Odisha, India.

${ }^{2}$ Department of Anatomy and Histology, Faculty of Veterinary and Animal Sciences, West Bengal University of Animal and Fishery Sciences, Kolkata, West Bengal, India.

${ }^{*}$ Corresponding author.e-mail: arunmandal_2005@yahoo.com.
} 
affect the normal bone growth, specifically elongation of long bones. This may lead to deformity of the bones. Some of the common health problems observed in broilers are skeletal disorders namely tibial dyschondroplasia (TD), which is due to growth plate cartilage anomaly (Williams et al. 2000, Farquharson and Jefferies 2000, Applegate and Lilburn 2002). Tibial dyschondroplasia is a disease of rapid growth rate that occurs in many avian species (Leach and Ornan 2007). The skeletal problems compromise the welfare of the birds, by reducing normal growth, increasing mortality and downgrading carcass quality, thus affecting overall performance of the broilers (Williams et al. 2000). There is high prevalence of such musculoskeletal disorders at the peak of long bone growth (Naldo et al. 2000). Abnormalities of broiler extremities cause important economic losses due to decreased weight gain and increased mortality (Rowland 1988).

An important factor in the diagnosis of skeletal abnormality is an understanding of the normal anatomy and development of the long bones. Generation of the base line data on morphometry of leg bones and associated growth plate cartilage can help address different skeletal deformities (specifically of long leg bones) like TD, ricket, fracture etc. Detailed gross

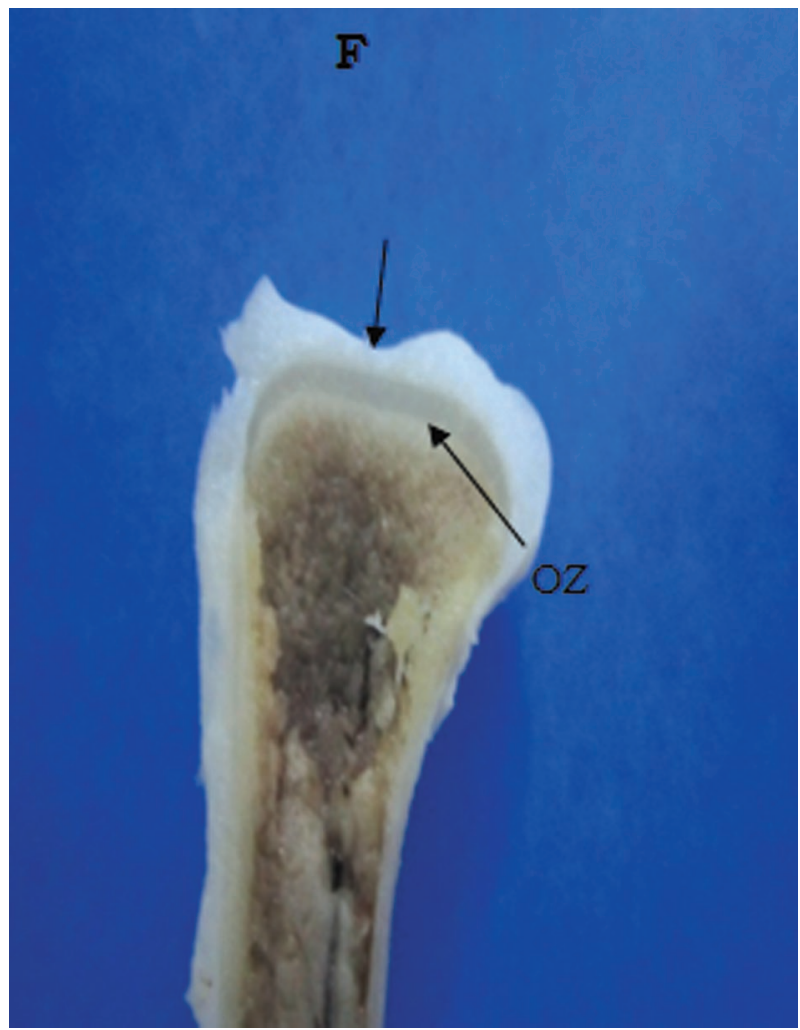

Fig. 1. Sectional view of femur (F) bone of 42 days old broiler chicken showing proximal growth plate cartilage with associated ossified zone (OZ) (arrows). morphometrical data on the long leg bones in broiler chickens are scarce. Literature on these data in Vencob broilers is lacking. In the context of the aforesaid facts, the present study was planned to carry out gross morphometrical studies on the long leg bones (femur, tibiotarsus and tarsometatarsus) and associated growth plate cartilages in Vencob broiler chicken at different ages (on days 1,7, 14, 21, 28, 35 and 42).

\section{MATERIALS AND METHODS}

For the present investigation, forty- five (45) day old male 'Vencob' broiler chicks were procured from Eastern Hatcheries Pvt. Ltd., Bhubaneswar, Odisha. The sexing of chicks was done by the conventional vent method, followed by wing banding. Accordingly, the chicks were reared up to 6 weeks (i.e. market age) under deep litter system in the experimental pen of the Department of Anatomy \& Histology, College of Veterinary Science \& A.H., O.U.A.T., Bhubaneswar. The routine management practice was followed that included housing, vaccination, medication and feeding. Birds were sacrificed by cervical dislocation. The specimen samples (Femur, tibiotarsus and tarsometatarsus bones, and associated growth plate cartilages) were collected after careful dissection.

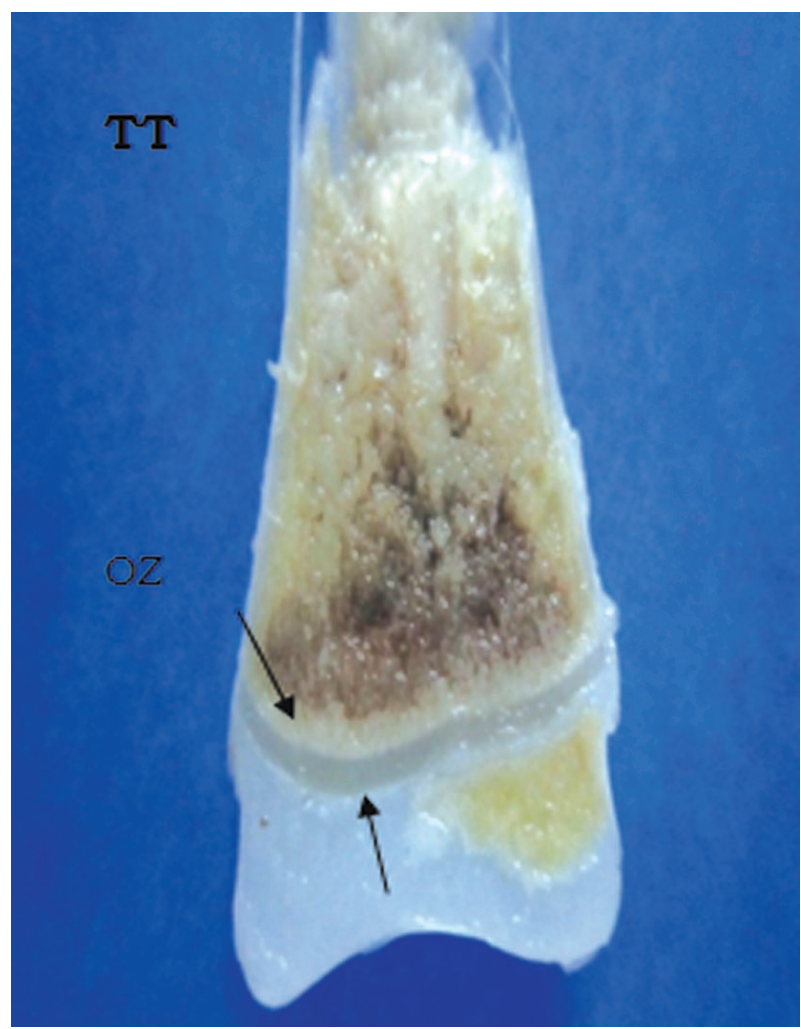

Fig. 2. Sectional view of tibio-tarsus (TT) bone of 42 days old broiler chicken showing distal growth plate cartilage with associated ossified zone (OZ) (arrows). 


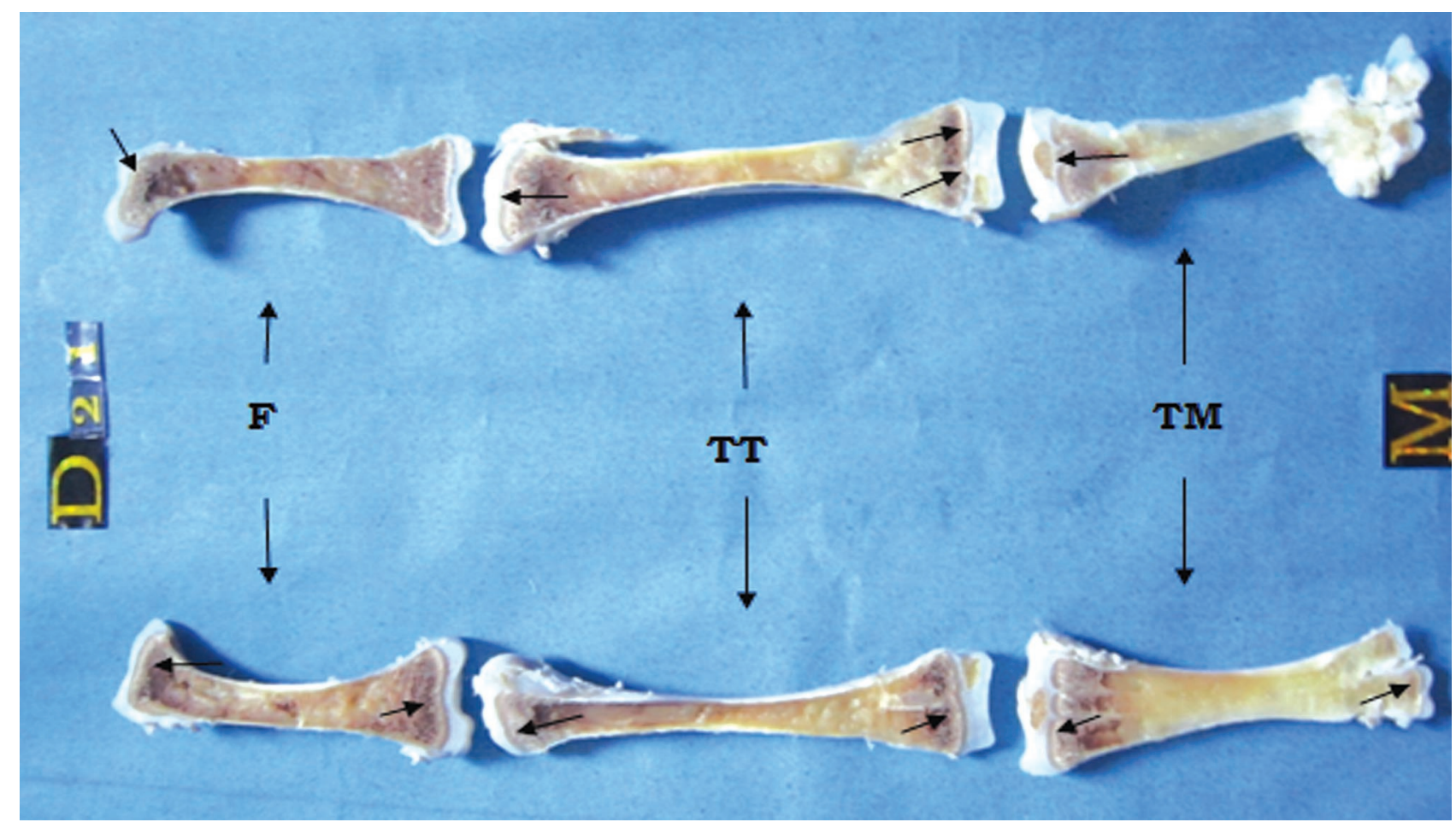

Fig. 3. Sectional view of right and left femur ( F), tibio-tarsus (TT ) \& tarso-metatarsus (TM) bones of 21 days old broiler chicken (male) showing growth plate cartilages (arrows).

\section{Gross morphometrical study}

Gross morphometrical parameters of the said bones under study included weight, length, width or diameter, width (thickness) of marrow cavity, thickness of cortical bone and growth plate cartilages (proximal and distal), and distance between proximal and distal growth plate cartilages and were measured in $\mathrm{mm}$ and $\mathrm{cm}$ (as required) with the help of a digital slide caliper, a non - distensible thread and a measuring tape (scale ruler). Six number (n $=06$ ) of samples were used for each measurement.

\section{Statistical analysis}

All the gross morphometrical data generated were subjected to the standard statistical analysis (Snedecor and Cochran 1989).

\section{RESULTS AND DISCUSSION \\ Gross morphometrical study of leg bones and associated growth cartilages}

\section{a) Femur}

The age - related changes in gross biometrical parameters of femur in post-hatch male broiler chicken are presented in Table 1.

The average weight of the femoral bones (right leg) in day - old male chicks gradually increased up to day 7 , followed by a marked increase from day 14 up to day 42 . The average weight of left femur in male broiler birds showed gradually increasing trend from day 7 till the end of the experimental period. There was insignificant difference $(p \geq 0.05)$ in weight of femoral bones when compared between right and left side.

There was concomitant increase in length of the right and left femoral bones in the birds during the post - hatch experimental period. However, there was insignificant difference $(p \geq 0.05)$ in length of femoral bones when compared between right and left side.

The diameter (width) of femur bones of both sides, in general, showed a gradual increase during the experimental period. The diameter at proximal end, mid shaft and distal end of right femur showed a steep increase $(p \geq 0.05)$ from day 7 up to day 21 and a steady increase thereafter till the end of the study period, i.e., day 42 . The bones of the left side showed almost similar trend. In both sides, the proximal and distal diameter increased more than the mid shaft diameter. The diameter of distal end was invariably greater than those of other two throughout the experimental period.

The size (thickness) of marrow cavity in the femoral bones of the either side revealed a marked increase from day 1 to day 7, followed by a gradual and steady rise thereafter till day 42 . The values for right and left bones 
Table 1. Age related changes in gross biometrical parameters of femur in post-hatch male broiler chickens.

\begin{tabular}{|c|c|c|c|c|c|c|c|c|}
\hline \multicolumn{2}{|l|}{ Parameters } & Day 1 & Day 14 & Day 21 & Day 28 & Day 35 & \multicolumn{2}{|l|}{ Day 42} \\
\hline \multicolumn{9}{|c|}{ Right } \\
\hline \multicolumn{2}{|l|}{ Weight (gm) } & $0.311 \pm 1.34$ & $0.711 \pm 1.42$ & $1.648 \pm 1.44^{*}$ & $3.542 \pm 1.3^{*}$ & $5.34 \pm 1.46^{*}$ & $7.362 \pm 1.52 *$ & $9.688 \pm 1.56$ \\
\hline \multicolumn{2}{|l|}{ Length $(\mathrm{cm})$} & $2.9 \pm 0.71$ & $3.2 \pm 0.73$ & $4.6 \pm 0.75^{*}$ & $5.8 \pm 0.74 *$ & $6.6 \pm 0.76^{*}$ & $7.6 \pm 0.79$ & $7.9 \pm 0.81$ \\
\hline \multirow{3}{*}{$\begin{array}{l}\text { Width/Diameter } \\
(\mathrm{mm})\end{array}$} & Proximal & $2.35 \pm 1.21^{*}$ & $3.94 \pm 1.23^{*}$ & $4.95 \pm 1.29^{*}$ & $8.64 \pm 1.30^{*}$ & $9.82 \pm 1.31$ & $10.64 \pm 1.33$ & $10.88 \pm 1.38$ \\
\hline & Mid shaft & $2.20 \pm 0.59^{*}$ & $3.38 \pm 0.61^{*}$ & $3.95 \pm 0.61 \mathrm{NS}$ & $5.15 \pm 0.63^{*}$ & $6.32 \pm 0.65$ & $6.59 \pm 0.69 \mathrm{NS}$ & $7.09 \pm 0.71$ \\
\hline & Distal & $2.98 \pm 1.07 *$ & $4.14 \pm 1.11^{*}$ & $5.19 \pm 1.21^{*}$ & $9.10 \pm 1.22 *$ & $10.11 \pm 1.24$ & $11.07 \pm 1.28$ & $11.15 \pm 1.31$ \\
\hline \multicolumn{2}{|c|}{ Marrow cavity (mm) } & $0.7 \pm 0.48 *$ & $1.59 \pm 0.49$ & $1.95 \pm 0.51 *$ & $2.79 \pm 0.50^{*}$ & $3.67 \pm 0.55$ & $3.85 \pm 0.59$ & $4.28 \pm 0.63$ \\
\hline \multirow{3}{*}{$\begin{array}{l}\text { Cortical bone } \\
\text { thickness }(\mathrm{mm})\end{array}$} & Proximal & $0.49 \pm 0.11$ & $0.60 \pm 0.12$ & $0.72 \pm 0.12$ & $0.80 \pm 0.15$ & $1.17 \pm 0.19$ & $1.22 \pm 0.21$ & $1.25 \pm 0.29$ \\
\hline & Mid shaft & $0.71 \pm 0.10$ & $0.87 \pm 0.11$ & $0.96 \pm 0.17$ & $1.15 \pm 0.19$ & $1.32 \pm 0.21$ & $1.38 \pm 0.22$ & $1.42 \pm 0.25$ \\
\hline & Distal & $0.51 \pm 0.11$ & $0.59 \pm 0.15$ & $0.63 \pm 0.17$ & $0.76 \pm 0.19$ & $1.19 \pm 0.21$ & $1.22 \pm 0.22$ & $1.25 \pm 0.29$ \\
\hline \multicolumn{2}{|c|}{$\begin{array}{l}\text { Distance between proximal \& } \\
\text { distal growth cartilage }(\mathrm{cm})\end{array}$} & -- & $2.4 \pm 0.96^{*}$ & $3.6 \pm 0.97 *$ & $5.3 \pm 0.99$ & $5.8 \pm 1.01^{*}$ & $6.8 \pm 1.07$ & $7.1 \pm 1.09$ \\
\hline \multirow{2}{*}{$\begin{array}{l}\text { Growth cartilage } \\
\text { thickness }(\mathrm{mm})\end{array}$} & Proximal & -1 & $0.62 \pm 0.10$ & $0.76 \pm 0.11^{3}$ & $0.94 \pm 0.13$ & $0.95 \pm 0.17$ & $0.85 \pm 0.21$ & $0.81 \pm 0.25$ \\
\hline & Distal & --- & $0.58 \pm 0.10$ & $0.72 \pm 0.11$ & $0.74 \pm 0.15$ & $0.85 \pm 0.17$ & $0.81 \pm 0.19$ & $0.79 \pm 0.21$ \\
\hline \multicolumn{9}{|c|}{ Left } \\
\hline \multicolumn{2}{|l|}{ Weight (gm) } & $0.313 \pm 1.33$ & $0.627 \pm 1.41^{*}$ & $1.892 \pm 1.42 *$ & $3.374 \pm 1.39^{*}$ & $5.309 \pm 1.4^{*}$ & $7.871 \pm 1.49^{*}$ & $9.637 \pm 1.55^{*}$ \\
\hline \multicolumn{2}{|l|}{ Length $(\mathrm{cm})$} & $2.8 \pm 0.72$ & $3.1 \pm 0.71^{*}$ & $4.6 \pm 0.73 *$ & $5.6 \pm 0.74^{*}$ & $6.8 \pm 0.75$ & $7.6 \pm 0.78$ & $7.7 \pm 0.79$ \\
\hline \multirow{3}{*}{$\begin{array}{l}\text { Width/Diameter } \\
(\mathrm{mm})\end{array}$} & Proximal & $2.32 \pm 1.31^{*}$ & $3.66 \pm 1.33^{*}$ & $5.61 \pm 1.34 *$ & $9.05 \pm 1.36^{*}$ & $10.40 \pm 1.37$ & $10.78 \pm 1.39$ & $10.82 \pm 1.40$ \\
\hline & Mid shaft & $1.88 \pm 0.29 *$ & $3.57 \pm 0.31^{*}$ & $4.77 \pm 0.32 *$ & $5.85 \pm 0.33^{*}$ & $6.93 \pm 0.33$ & $7.38 \pm 0.36$ & $7.75 \pm 0.39$ \\
\hline & Distal & $2.89 \pm 1.27$ & $3.96 \pm 1.29 *$ & $6.88 \pm 1.22 *$ & $9.21 \pm 1.30^{*}$ & $10.59 \pm 1.33$ & $10.96 \pm 1.38$ & $11.05 \pm 1.41$ \\
\hline \multicolumn{2}{|c|}{ Marrow cavity (mm) } & $0.83 \pm 0.46^{*}$ & $1.74 \pm 0.49$ & $2.24 \pm 0.51$ & $3.14 \pm 53$ & $4.00 \pm 0.56$ & $4.25 \pm 0.58$ & $4.54 \pm 0.61$ \\
\hline \multirow{3}{*}{$\begin{array}{l}\text { Cortical bone } \\
\text { thickness }(\mathrm{mm})\end{array}$} & Proximal & $0.66 \pm 0.10$ & $0.76 \pm 0.11$ & $0.83 \pm 0.12$ & $0.95 \pm 0.13$ & $1.25 \pm 0.19$ & $1.28 \pm 0.21$ & $1.30 \pm 0.25$ \\
\hline & Mid shaft & $0.53 \pm 0.10$ & $0.84 \pm 0.13$ & $1.22 \pm 0.15$ & $1.35 \pm 0.17$ & $1.50 \pm 0.19$ & $1.55 \pm 0.21$ & $1.59 \pm 0.26$ \\
\hline & Distal & $0.6 \pm 0.11$ & $0.68 \pm 0.13$ & $0.76 \pm 0.15$ & $0.84 \pm 0.17$ & $1.22 \pm 0.19$ & $1.25 \pm 0.22$ & $1.30 \pm 0.23$ \\
\hline \multicolumn{2}{|c|}{$\begin{array}{l}\text { Distance between proximal \& } \\
\text { distal growth cartilage }(\mathrm{cm})\end{array}$} & --- & $2.6 \pm 0.89^{*}$ & $3.7 \pm 0.91^{*}$ & $5.2 \pm 0.93^{*}$ & $5.8 \pm 0.95$ & $6.6 \pm 0.96$ & $6.9 \pm 0.99$ \\
\hline Growth cartilage & Proximal & -- & $0.41 \pm 0.11$ & $0.6 \pm 0.10$ & $0.88 \pm 0.12$ & $0.98 \pm 0.15$ & $0.88 \pm 0.19$ & $0.75 \pm 0.23$ \\
\hline thickness (mm) & Distal & -- & $0.38 \pm 0.11$ & $0.56 \pm 0.12 \ldots$ & $-0.79 \pm 0.13$ & $0.91 \pm 0.16$ & $0.85 \pm 0.17$ & $0.78 \pm 0.19$ \\
\hline
\end{tabular}

*Values in a row vary significantly $(\mathrm{p} \leq 0.05)$ and rest of the values in a row as well as the values for the same parameter in a column (between right and left) show non-significant variation $(\mathrm{p} \geq 0.05)$. 
Gross morphometrical changes in leg bones of post-hatch male broiler chickens...

Table 2. Age related changes in gross biometrical parameters of tibio-tarsus in post-hatch male broiler chickens.

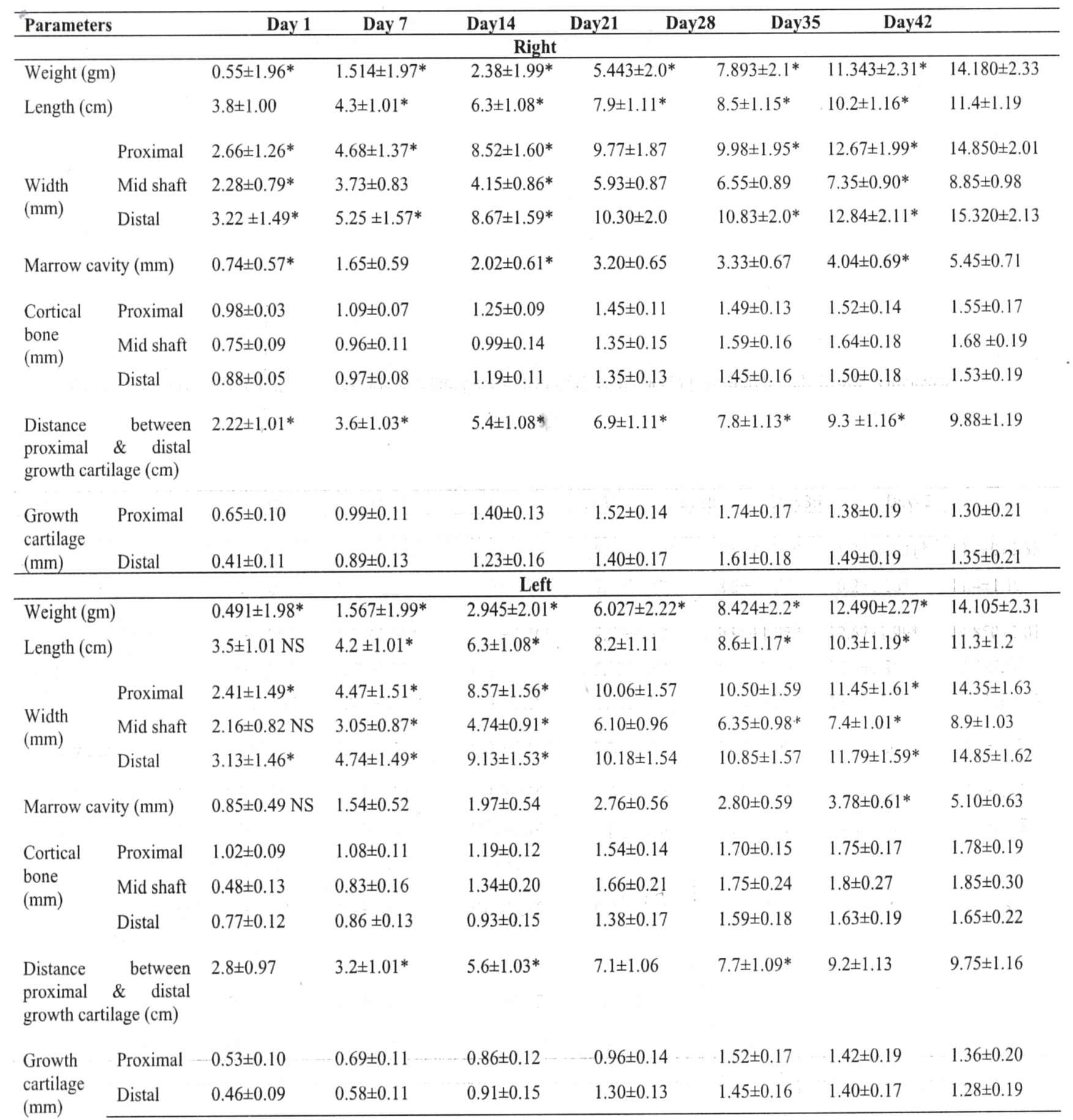

\footnotetext{
* Values in a row vary significantly $(\mathrm{p} \leq 0.05)$ and rest of the values in a row as well as the values for the same parameter in a column (between right and left) show non-significant variation $(\mathrm{p} \geq 0.05)$.
} 
Exploratory Animal and Medical Research, Vol.11, Issue 2, December, 2021

Table 3. Age related changes in gross biometrical parameters of tarso-metatarsus in post-hatch male broiler chickens.

\begin{tabular}{|c|c|c|c|c|c|c|c|c|}
\hline \multicolumn{2}{|c|}{ Parameters } & Day 1 & Day 7 & Day14 & Day21 & Day28 & Day35 & Day42 \\
\hline \multicolumn{9}{|c|}{ Right } \\
\hline \multicolumn{2}{|c|}{ Weight (gm) } & $0.318 \pm 1.23$ & $0.409 \pm 1.29 *$ & $1.612 \pm 1.31^{*}$ & $3.309 \pm 1.35^{*}$ & $5.067 \pm 1.3^{*}$ & $7.474 \pm 1.39^{*}$ & $9.593 \pm 1.41$ \\
\hline \multicolumn{2}{|c|}{ Length (cm) } & $2.7 \pm 0.86$ & $3.2 \pm 0.89^{*}$ & $4.7 \pm 0.91^{*}$ & $6.2 \pm 0.92$ & $6.67 \pm 0.97^{*}$ & $8.3 \pm 0.99$ & $9.1 \pm 1.01$ \\
\hline \multirow{3}{*}{$\begin{array}{l}\text { Width/Di } \\
\text { ameter } \\
(\mathrm{mm})\end{array}$} & Proximal & $4.22 \pm 1.39 *$ & $5.77 \pm 1.42 *$ & $9.93 \pm 1.45^{*}$ & $10.71 \pm 1.49$ & $11.15 \pm 1.51^{*}$ & $14.11 \pm 1.53$ & $14.88 \pm 1.56$ \\
\hline & Mid shaft & $2.81 \pm 0.92 *$ & $4.43 \pm 0.96$ & $5.32 \pm 0.99 *$ & $7.40 \pm 1.01$ & $8.10 \pm 1.05^{*}$ & $9.3 \pm 1.08$ & $9.85 \pm 1.11$ \\
\hline & Distal & $4.06 \pm 1.39^{*}$ & $5.59 \pm 1.41 *$ & $9.44 \pm 1.43$ & $10.32 \pm 1.45$ & $10.90 \pm 1.47^{*}$ & $13.86 \pm 1.49$ & $14.25 \pm 1.52$ \\
\hline \multicolumn{2}{|c|}{ Marrow cavity (mm) } & $1.30 \pm 0.69^{*}$ & $2.4 \pm 0.72$ & $2.96 \pm 0.73^{*}$ & $4.07 \pm 0.77^{*}$ & $5.18 \pm 0.79^{*}$ & $6.29 \pm 0.83 \mathrm{NS}$ & $6.75 \pm 0.86$ \\
\hline \multirow{3}{*}{$\begin{array}{l}\text { Cortical } \\
\text { bone } \\
(\mathrm{mm})\end{array}$} & Proximal & $0.94 \pm 0.03$ & $1.09 \pm 0.05$ & $1.15 \pm 0.06$ & $1.33 \pm 0.07$ & $1.40 \pm 0.11$ & $1.45 \pm 0.12$ & $1.48 \pm 0.14$ \\
\hline & Mid shaft & $0.73 \pm 0.04$ & $1.06 \pm 0.06$ & $1.18 \pm 0.09$ & $1.35 \pm 0.11$ & $1.45 \pm 0.12$ & $1.5 \pm 0.12$ & $1.53 \pm 0.13$ \\
\hline & Distal & $0.93 \pm 0.03$ & $1.15 \pm 0.04$ & $1.20 \pm 0.05$ & $1.27 \pm 0.07$ & $1.42 \pm 0.09$ & $1.45 \pm 0.11$ & $1.46 \pm 0.15$ \\
\hline \multirow{4}{*}{$\begin{array}{l}\text { Distance } \\
\text { proximal } \\
\text { growth ca } \\
\text { Growth } \\
\text { cartilage } \\
(\mathrm{mm})\end{array}$} & $\begin{array}{l}\text { between } \\
\& \quad \text { distal } \\
\text { lage }(\mathrm{cm})\end{array}$ & --- & $2.6 \pm 1.01$ & $3.2 \pm 1.03 *$ & $4.8 \pm 1.04 *$ & $5.8 \pm 1.09^{*}$ & $7.0 \pm 1.13$ & $7.9 \pm 1.17$ \\
\hline & Proximal & $0.57 \pm 0.08$ & $0.85 \pm 0.09$ & $1.14 \pm 0.12$ & $1.32 \pm 0.15$ & $1.66 \pm 0.17$ & $1.58 \pm 0.18$ & $1.53 \pm 0.21$ \\
\hline & Distal & -- & $0.28 \pm 0.03$ & $0.42 \pm 0.05$ & $0.55 \pm 0.07$ & $0.59 \pm 0.09$ & $0.44 \pm 0.11$ & $0.40 \pm 0.17$ \\
\hline & & & & Left & & & & \\
\hline \multicolumn{2}{|c|}{ Weight (gm) } & $0.376 \pm 1.22$ & $0.387 \pm 1.27^{*}$ & $1.812 \pm 1.30^{*}$ & $5.183 \pm 1.48^{*}$ & $6.887 \pm 1.46^{*}$ & $8.548 \pm 1.38^{*}$ & $9.823 \pm 1.39$ \\
\hline \multicolumn{2}{|c|}{ Length (cm) } & $2.5 \pm 0.84$ & $2.9 \pm 0.88^{*}$ & $4.8 \pm 091^{*}$ & $6.3 \pm 0.93 \mathrm{NS}$ & $6.8 \pm 0.95^{*}$ & $8.1 \pm 0.98$ & $8.9 \pm 0.99$ \\
\hline \multirow{3}{*}{$\begin{array}{l}\text { Width/Di } \\
\text { ameter } \\
(\mathrm{mm})\end{array}$} & Proximal & $4.09 \pm 1.38^{*}$ & $5.10 \pm 1.41^{*}$ & $8.83 \pm 1.47^{*}$ & $10.53 \pm 1.57^{*}$ & $11.72 \pm 1.51^{*}$ & $14.33 \pm 1.52$ & $14.61 \pm 1.56$ \\
\hline & Mid shaft & $3.51 \pm 0.85$ & $4.41 \pm 0.87^{*}$ & $5.51 \pm 0.89^{*}$ & $7.41 \pm 0.91$ & $8.16 \pm 0.98^{*}$ & $9.24 \pm 1.07$ & $9.74 \pm 1.10$ \\
\hline & Distal & $4.10 \pm 1.37$ & $4.93 \pm 1.38^{*}$ & $8.31 \pm 1.42 *$ & $9.90 \pm 1.49$ & $10.85 \pm 1.47^{*}$ & $13.81 \pm 1.48$ & $14.12 \pm 1.49$ \\
\hline \multicolumn{2}{|c|}{ Marrow cavity (mm) } & $1.91 \pm 0.66$ & $2.60 \pm 0.67$ & $3.2 \pm 0.68 *$ & $4.73 \pm 0.68$ & $5.20 \pm 0.71$ & $6.14 \pm 0.73$ & $6.58 \pm 0.78$ \\
\hline \multirow{3}{*}{$\begin{array}{l}\text { Cortical } \\
\text { bone } \\
(\mathrm{mm})\end{array}$} & Proximal & $0.91 \pm 0.03$ & $1.03 \pm 0.05$ & $1.12 \pm 0.07$ & $1.25 \pm 0.09$ & $1.44 \pm 0.10$ & $1.48 \pm 0.11$ & $1.52 \pm 0.13$ \\
\hline & Mid shaft & $0.77 \pm 0.02$ & $0.85 \pm 0.05$ & $1.15 \pm 0.11$ & $1.31 \pm 0.12$ & $1.49 \pm 0.11$ & $1.55 \pm 0.13$ & $1.58 \pm 0.13$ \\
\hline & Distal & $1.01 \pm 0.01$ & $1.13 \pm 0.03$ & $1.18 \pm 0.05$ & $1.27 \pm 0.06$ & $1.33 \pm 0.08$ & $1.4 \pm 0.11$ & $1.44 \pm 0.14$ \\
\hline $\begin{array}{l}\text { Distance } \\
\text { proximal } \\
\text { growth cart }\end{array}$ & $\begin{array}{l}\text { between } \\
\& \quad \text { distal } \\
\text { lage }(\mathrm{cm})\end{array}$ & -- & $2.4 \pm 0.99 *$ & $3.8 \pm 1.01^{*}$ & $5.7 \pm 1.06$ & $6.1 \pm 1.07^{*}$ & $7.3 \pm 1.11$ & $7.7 \pm 1.15$ \\
\hline \multirow{2}{*}{$\begin{array}{l}\text { Growth } \\
\text { cartilage } \\
(\mathrm{mm})\end{array}$} & Proximal & $-0.54 \pm 0.06$ & $0.89 \pm 0.08$ & $1.06 \pm 0.11$ & $1.23 \pm 0.12$ & $1.43 \pm 0.15$ & $1.36 \pm 0.18$ & $1.30 \pm 0.20$ \\
\hline & Distal & --- & $0.62 \pm 0.08$ & $0.74 \pm 0.09$ & $0.95 \pm 0.17$ & $1.32 \pm 0.16$ & $1.23 \pm 0.18$ & $1.19 \pm 0.21$ \\
\hline
\end{tabular}

* Values in a row vary significantly $(\mathrm{p} \leq 0.05)$ and rest of the values in a row as well as the values for the same parameter in a column (between right and left) show non-significant variation $(\mathrm{p} \geq 0.05)$. 
became almost double on day 7 as compared to that of day 1 . Then there was a progressive increase in the bone marrow size till day 42. However, the growth slowed down a bit in older birds. The average thickness of cortical bone (proximal, mid shaft and distal) of the either side revealed a general trend of gradual increase in the birds. The thickest cortical bone was recorded in the eldest birds (on day 42). Though initially mid shaft cortical bone was thinner than epiphyseal ends, it gradually overtook to become thicker from day 21 till the end of experimental period. Age -wise variation and variation between right and left side bones were insignificant $(\mathrm{p} \geq 0.05)$.

The growth plate cartilage could not be traced (identified) grossly in the femur of both sides on day 1 . However, from day 7 till day 42 the same could be easily traced and studied for gross parameters on sectional view of the bones (Fig. 1). In consistent with the increase in length of the bone, the distance between proximal and distal growth plate cartilage also showed a gradual increase (far away from each other) from day 7 onward and reached the highest respective values on day 42 . The thickness of growth plate cartilage gradually and slowly increased with age (from day 7 onward up to day 28) in bones of both sides. Thereafter, the growth plate cartilages became slightly thinner. There was minor variation $(\mathrm{p} \geq$ 0.05 in thickness between proximal and distal growth plate cartilages at a given age.

The present findings on different gross morphometrical parameters in broiler chickens corroborate well with the observations of earlier workers. The weight, length and diameter of femur as recorded earlier by Rutten et al. (2002) in meat type Hubbard chickens on day 19 and Breugelmans et al. (2007) in 42 days old broiler chickens are nearly similar to the present finding. Robison et al. (2015) reported linear increase in length and width of femur with age in case of ducks, who recorded almost similar data as observed in the present study. The minor difference in these values may be due to strain or breed variation of the broiler birds studied as well as variable management and feeding practice offered.

\section{b) Tibiotarsus}

The age - related changes in gross biometrical parameters of tibiotarsus in post-hatch male broiler chicken are presented in Table 2.

The average weight of the tibiotarsal bones (right and left side) in day old male chicks sharply increased ( $\mathrm{p} \leq$ 0.05 ) on day 7 and followed this increasing trend up to day 42 . There was simultaneous increase in length of the bones like that of femur throughout the experimental period and was significant $(\mathrm{p}=0.05)$ except at first and last week.

The diameter (width) of tibiotarsal bones of both sides, in general, showed a gradual increase during the experimental period. The diameter at proximal end, mid shaft and distal end of right and left tibiotarsus showed almost similar trend like that of femur. The mid shaft diameter followed a gradual and steady increase from day 1 to day 42 .

The size (thickness) of marrow cavity in the tibiotarsal bones of both sides revealed a steep increase from day 1 to day 7 , followed by a gradual and steady rise thereafter till day 42. However, its growth was slower $(p \geq 0.05)$ between day 21 and 28 . The size of bone marrow followed a similar pattern like that of femur with advancement of age of the birds.

The average thickness of cortical bone (proximal, mid shaft and distal) of either side revealed a general trend of gradual increase $(\mathrm{p} \geq 0.05)$ in post - hatch broiler chickens, with slight slowdown towards the end of the study period i.e., days 35 and 42 . Though initially mid shaft cortical bone was thinner than epiphyseal ends, it gradually became thicker from day 28 till the end of experimental period.

The growth plate cartilage was identified on gross observation in the tibiotarsus of all the day old chicks under study. However, from day 7 till day 42 the same was easily identified and studied grossly on sectional (longitudinal) view of the bones (Fig. 2). The distance between proximal and distal growth plate cartilages also showed a gradual increase from day 7 onward like that of femur bones. The trend in change or variation $(\mathrm{p} \geq$ 0.05 ) in thickness of growth plate cartilage in bones of both sides at different ages appeared similar to that observed in case of femur bones.

The present observations on different gross dimensions of tibiotarsus bones (namely weight, length and diameter or width) in broiler chickens are well comparable with those reported by Rose et al. (1996), Leterrier and Constantin (1999), Williams et al. (2000), Rutten et al. (2002), Breugelmans et al. (2007), Shim et al. (2012), Paxton et al. (2014), Vijayakumar and Balakrishnan (2014) and Robison et al. (2015) in different meat type domestic birds (chicken and duck). These biometrical values on tibiotarsus of male Ross 308 broiler chicken as observed by Charuta et al. (2013) are in agreement with the present findings. The slight variation in these values might be attributed to the strain or breed variation of the chicken as well as due to difference in feeding and management practice, as also opined earlier by Noy and 
Sklan (1999), Handerson et al. (2008) and Coto et al. (2008). However, the literature on the detailed side - and age - wise variation in different gross morphometrical parameters is lacking to be compared with and discussed on.

\section{c) Tarsometatarsus}

The age - related changes in gross biometrical parameters of tarsometatarsus in post-hatch male broiler chicken are presented in Table 3.

The average weight of the tarsometatarsus bones of right and left legs in day old chicks gradually increased up to day 7 , followed by a marked increase from day 14 to day 42 i.e., till the end of the experimental period (as also observed in case of femoral and tibiotarsus bones). There was insignificant difference $(p \geq 0.05)$ in weight of tarsometarsal bones when compared between right and left side.

The right as well as left side bones of the birds elongated concomitantly like that of femur during the post - hatch experimental period. There was simultaneous lengthening of left tarsometatarsal bones in the birds under study like that of right ones. The side - wise variation was similar to that of femur and tibiotarsus bones.

The tarsometatarsus bones of both sides, in general, gradually increased $(\mathrm{p} \geq 0.05)$ in diameter throughout the experimental period. The diameter at proximal end, mid shaft and distal end of right and left side bones showed almost similar trend like that of femur and tibiotarsus.

The size (thickness) of marrow cavity in the tarsometatarsal bones of both sides revealed a steep increase ( $\mathrm{p} \leq 0.05$ ) from day 1 to day 7 , followed by a gradual and steady rise thereafter till the end of experimental period. However, its growth slowed down $(p \geq 0.05)$ between day 35 and 42 . The size of bone marrow followed a similar pattern like that of femur and tibiotarsus with age of the birds.

The average thickness of cortical bone (proximal, mid shaft and distal) of either side revealed a general trend of gradual increase in post - hatch broiler chickens. It slightly slowed down towards the end of the study period i.e., day 35 and 42 . Though initially mid shaft cortical bone was thinner than epiphyseal ends, it gradually became thicker from day 21 till the end of experimental period.

Though the proximal growth plate cartilage was identified, the distal one could not be traced grossly in the tarsometatarsus of both sides on day 1 . However, from day 7 till day 42 the same were easily observed and studied for gross parameters on sectional view of the bones (Fig. 3). The distance between proximal and distal growth cartilage showed a gradual increase $(\mathrm{p} \leq 0.05)$ from day 7 onward like that of femur and tibiotarsal bones. The trend in change or variation in thickness of growth plate cartilage in bones of both sides at different ages appeared similar to that observed in case of femur and tibiotarsus.

Some of the gross morphometrical values (namely length and width) on tarsometatarsus in the present study agree with those observed by Breugelmans et al. (2007) in broiler chickens of 7 weeks of age.

From the present observations, it is evident that the age - wise variation in different gross morphometrical dimesions (weight, length, diameter or width of the bones and thickness of marrow cavity, cortical bone and growth plate cartilage etc. followed almost a similar trend in all the bones under study (femur, tibiotarsus and tarsometatarsus).

Elongation of all these appendicular long bones continued with advancement of age of the birds till day 42 , i.e., as long as the growth plates were present. This is due to the fact that lengthening of long bones occurs at the expense of growth cartilage plates and increase in length of the bone ceases after closure of the growth plate cartilage. Similar opinion was put forth by Getty (1975), Farquharson and Jefferies (2000), Nilsson et al. (2005), Akers and Denbow (2008), Dyce et al. (2009), Villemure and Stokes (2009) in domestic animals as well as birds.

The presence of growth plate cartilages was doubly confirmed by simultaneous radiographic as well as histomorphological observations along with gross anatomical finding in the present study.

Increase in diameter of the long bones is the result of intramembranous ossification effected by deposition of bony matrix by appositional method on the periosoteal surface of the bone. At the same time bone resorption on endosteal surface results in enlargement of marrow cavity. This process called bone modeling continues till the bone attains its definite shape (Banks 1993, Eurell and Sickle 1998, Dyce et al. 2009). Different morphometrical parameters of the leg bones increased simultaneously with age as well as with increase in body weight of the broiler birds. Moprphometrical dimensions of the long leg bones like length, width etc. are considered as good and reliable indicators of musculoskeletal growth in broiler chicken (Naldo et al. 2000, Williams et al. 2000, Appplegate and Lilburn 2002).

The general gross morphological features of these three leg bones in the present study are similar to the text description of Getty (1975), Dyce et al. (2009) and Ghosh (2018). 
Gross morphometrical changes in leg bones of post-hatch male broiler chickens...

\section{CONCLUSION}

The average weight, length, size (thickness) of marrow cavity and cortical bone thickness in all the bones gradually increased with age of the broiler birds. The diameter (width) of all the bones in broiler birds showed a steep increase from day 7 up to day 21 and a steady increase thereafter till day 42 . The proximal and distal end widened more than the mid shaft and the distal end was the widest. The growth of the gross dimensions of the bones slowed down a bit towards the end of the experiment (days 35 and 42). Though initially mid shaft cortical bone was thinner than epiphyseal ends, it gradually became thicker from day 21 (in femur and tarsometatarsus) or from day 28 (in tibiotarsus) till day 42. The gross morphological observation did not reveal the presence of growth plate cartilages in all day - old chicks. In femur, presence of growth plate cartilage was reported for the first time. Moprphometrical parameters (dimensions) of the long leg bones like length, width etc. are considered as good and reliable indicators of musculoskeletal growth in broiler chicken and can even be correlated with the common skeletal abnormalities, specifically those of long leg bones for better understanding.

\section{ACKNOWLEDGEMENT}

The authors are very much grateful to the Dean, C.V. Sc. and A.H., OUAT, Bhubaneswar for providing necessary facilities to carry out the research work.

\section{REFERENCES}

Akers R M, Denbow D M (2008) Anatomy and physiology of domestic animals. $1^{\text {st }}$ edn. Blackwell Publishing, USA \& UK.

Applegate TJ, Lilburn S (2002) Growth of the femur and tibia of a commercial broiler line. Poult Sci 81: 1289-1294.

Banks WJ (1993) Supportive tissues - bone. In: Applied veterinary histology. ${ }^{\text {rd }}$ edn. Mosby Year Book Inc., Baltimore.

Breugelmans S, Muylle S, Cornillie P, Saunders J, Simoens P (2007) Age determination of poultry: a challenge for customs. Vlaams Dierg Tijd 76: 423-430.

Charuta A, Dzierzecka, Komosa, M, Kalinowski L, Pierzcha M (2013) Age- and sex-related differences of morphometric, densitometric and geometric parameters of tibiotarsal bone in ross broiler chickens. Folia Biol (Krakow) 61: 211-220.

Coto C, Yan F, Cerrate S, Wang Z, Sacakli P et al. (2008) Effects of dietary levels of calcium and nonphytate phosphorus in broiler starter diets on live performance, bone development and growth plate conditions in male chicks fed a corn-based diet. Int J Poult Sci 7 (7): 638-645.

Dyce KM, Sack WO, Wensing CJG (2009) Textbook of veterinary anatomy, $3^{\text {rd. }}$ edn. (Indian), Saunders Elsevier, Noida, India.

Eurell JAC, Sickle DCV (1998) Connective and supportive tissues. In: Text book of veterinary histology. (eds.) Dellman HD, Eurell JA, $5^{\text {th }}$ edn. Williams and Wilkins, Philadelphia, London.

Farquharson C, Jefferies D (2000) Chondrocytes and longitudinal bone growth: The development of tibial dyschondroplasia. Poult Sci 79: 994-1004.

Getty R (1975) General osteology. In: Sisson and Grossman's The anatomy of the domestic animals. Vol. I, $5^{\text {th }}$ edn. W.B. Saunders Company, Philadelphia.

Ghosh RK (2018) Primary veterinary anatomy. $7^{\text {th }}$ edn. Current Books International, Kolkata, Chennai, Mumbai.

Handerson SN, Vincente JL, Pixiey CM, Hargis BM, Tellez G (2008) Effect of an early nutritional supplement of broiler performance. Int J Poult Sci 7: 211-214.

Kirkwood JK, Duignan PJ, Kember NF, Bennet PM, Price DJ (1989) The growth rate of the tarsometatarsus bone in birds. J Zoology London 217: 403-416.

Leach RM jr, Ornan EM (2007) Tibial dyschondroplasia 40 years later. Poult Sci 86: 2053-2058.

Leterrier C, Constantin P (1999) Early bone growth in chickens genetically selected for a high and low growth rate. Growth Dev Aging 63(3): 75-84.

Manohar GR, Omprakash AV, Kanagaraju P (2015) Leg weakness in commercial broiler chicken an overview. Int J Sci Environ Tech 4(2): 482-487.

Naldo L, Baile TA, Samour JH (2000) Radiographic analysis of the growth rate of long bones in bustards. Res Vet Sci 69: 233-240.

Nilsson O, Milchum RDJr, Schrier L, Ferns SP, Barnes KM et al. (2005) Growth plate senescence is associated with loss of DNA methylation. J Endocrinol 186: 241-249.

Noy Y, Sklan D (1999) Different types of early feeding and performance in chicks and poults. J Appl Poult Res 8:16-24.

Paxton H, Tickle PG, Rankin JW, Codd JR, Hutchinson JR (2014) Anatomical and biomechanical traits of broiler chickens 
across ontogeny. Part II: Body segment inertial properties and muscle architecture of the pelvic limb. Peer J e $473: 1-24$.

Robison CI, Rice M, Makagon MM, Karcher DM (2015) Duck gait: relationship to hip angle, bone ash, bone density, and morphology. Poult Sci 94: 1060-1067.

Rose N, Constantin P, Leterrier C (1996) Sex differences in bone growth of broiler chickens. Growth Dev Aging 60(2): 4959.

Rowland GN (1988) Leg problems in broilers and broiler breeders (Skeletal system). Ind River Intl Breeder Update, iv(1).

Rutten M, Leterrier C, Constantin P, Reiter K, Bessei W (2002) Bone development and activity in chickens in response to reduced weight-load on legs. Anim Res 51: 327-336.

Shim MY, Karnuah AB, Anthony NB, Pesti GM, Aggrey SE (2012) The effects of broiler chicken growth rate on valgus, varus, and tibial dyschondroplasia. Poult Sci 91: 62-65.
Snedecor GW, Cochran WG (1989) Statistical methods. $9^{\text {th. }}$ edn. The Iowa State University Press, Ames, Iowa.

Sreeranjini AR, Ashok N, Indu VR, Lucy KM, Maya S et al. (2013) Morphological studies on the femur, tibiotarsus and fibula of pea hen (Pavo cristatus). Tamilnadu J Vet Anim Sci 9(4): 248-252.

Vijayakumar MP, Balakrishnan V (2014) Evaluating the bioavailability of calcium phosphate nanoparticles as mineral supplement in broiler chicken. Ind J Sci Tech 7(10): 1475-1480.

Villemure I, Stokes IAF (2009) Growth plate mechanics and mechanobiology. A survey of present understanding. J Biomech 42: 1793-1803.

Williams B, Solomon S, Waddington D, Thorp B, Farquharson C (2000) Skeletal development in the meat-type chicken. Brit Poult Sci 41: 141-149.

*Cite this article as: Behera M, Sathapathy S, Mandal AK (2021) Gross morphometrical changes in leg bones of post-hatch male broiler chickens with special reference to growth plate cartilage. Explor Anim Med Res 11(2): 188197. DOI : 10.52635/eamr/11.2.188-197. 